\title{
دور الأسرة العراقية في تنمية بعض القيم الاجتماعية \\ الايجابية لدى الأطنال من وجهة نظر المعلمات والمعلمين
}

م.د. غادة علي أل هاشم/ كلية التربية ابـن رشد اللعلوم /جامعة بـغداد / قسم العلوم التربوية والنفسية م.م. هدى هسن مهمد وزارة التربية / مديرية الرصافة الأولى / قسم شمال بـغداد

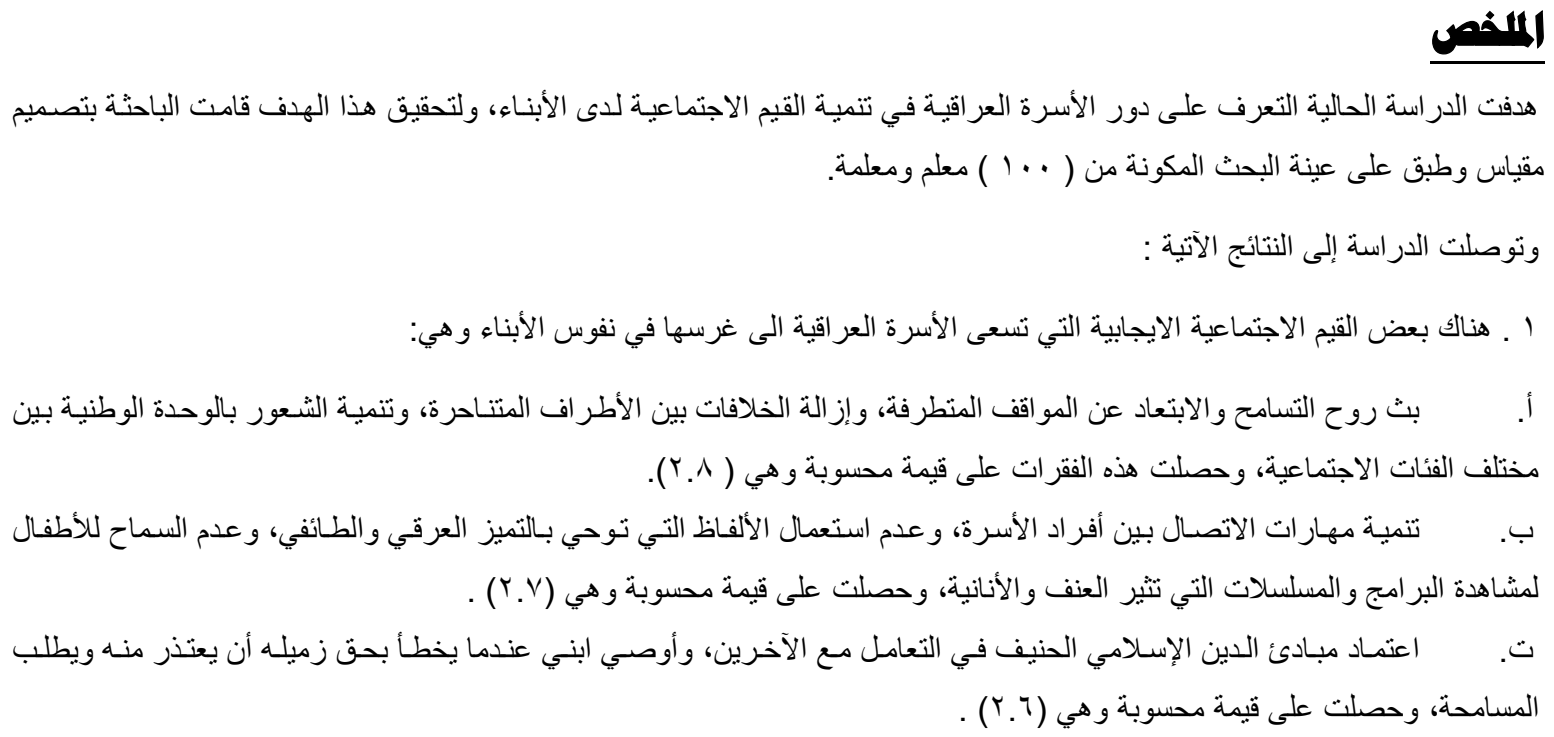

\section{Abstract}

The present study aimed to identify the role of the Iraqi family in the development of social values among the children, and to achieve this goal, the researcher scale design and applied research sample consisting of (100) teachers.

The study found the following results:

1. There are some positive social values that the Iraqi family is seeking to be planted in the souls of the children, namely:

a. Spread the spirit of tolerance and to stay away from extreme positions, removing the differences between the warring parties, and develop a sense of national unity among the various social groups, and got these paragraphs on the calculated value of which (2.8).

B. Development of communication skills between family members, and not to use words that suggest ethnic and sectarian excellence, and do not allow children to watch soap operas and programs that give rise to violence and selfishness, and got on a calculated value (2.7).

T. Adoption of the principles of the Islamic religion in dealing with others, I recommend my son when faulting the right colleague to apologize and ask forgiveness from him, and I got a calculated value (2.6).

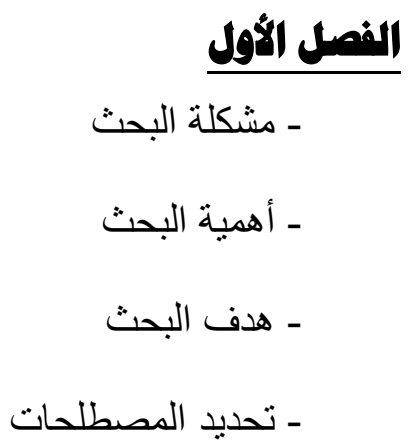




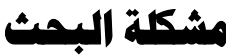

تسهم التنشئة الاجتماعية الجيدة في جعل الفرد يشعر بمسؤولياته تجاه نفسه واتجاه الآخرين عن طريق تعليمه الأدوار الاجتماعية والمعايير الاجتماعيـة التي تحدد هذه الأدوار، إذ يتعلم كيف يسلك سلوكاً اجتماعياً

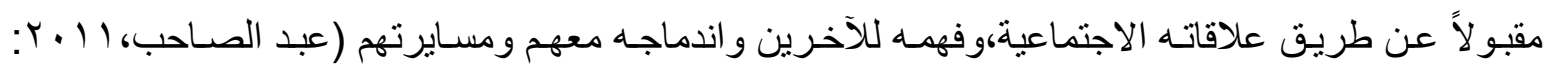

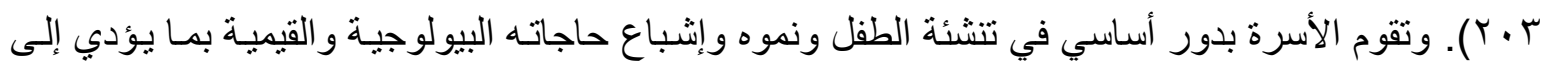

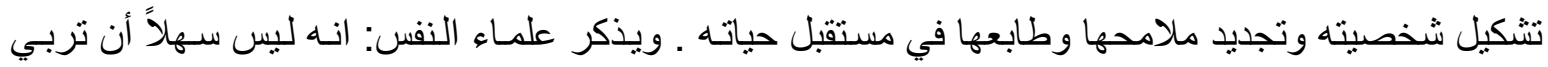
طفلاً في زمانتا المشحون بالتوتر وضيق الوقت.

إن الطفل العر اقي لا يعيش بمعزل عن مجتمعه بل هو نتاج لمجتمع أُسري صغير، ولا ونما وترعرع

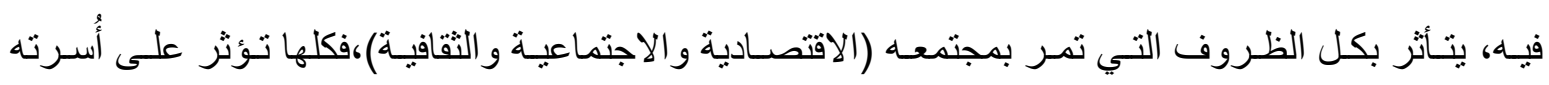
وبالتالي يتأثر بها، وتعد الأسرة العماد الأول للمجتمع والمحصن التربوي الأول التي يتخرج منه الفرد النافع للمجتمع ولنفسه ولوطنه، و الأسرة أول بيئة تستقبل الطفل وفيها يتم تكوين قدر اتـه المختلفة وتتكيل العناصر

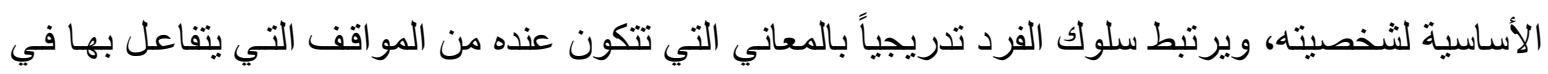
أسرته ومحيطه والطفل يتأثر بهذه الظروف وتصساغ شخصيته في مر احلها الأولى ويصبح جزءاً من كيانها

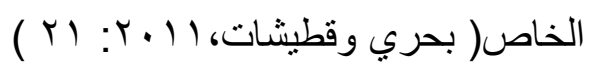

إن من دواعي اهتمامنا بهذا الموضوع ما ترتب على الظروف الر اهنـة من آثنار خطيرة على منظومـة القيم، فقد تم تكريس قيم المصلحة الذاتية على المصلحة العامـة ومن ثم انهارت المعايير التي كنا نقيم بها لتها سلوكنا وتصرفاتنا، وبدأت تثيع القيم السلبية من نفعية ومادية وتفاخر و استغلال للآخرين . وبنـاء على مـا تقدم ذكره فـان الباحثة تحساول في دراسـة دور الأسـرة العر اقيـة في تتميـة بعض القيم الاجتماعية الايجابية.

\section{أهميمية البمث والصاجة إليه}

المحبـة والمـودة .. المعاملـة و المعاثـرة الطيبـة والمو عظـة الحســة آداب إسـلامية أصـيلة وركـائز

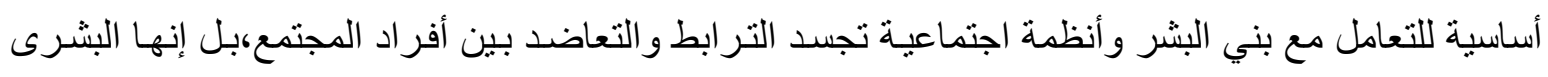
التي حملها رسولنا الكريم محمد(صلى الله عليه وسلم) و الهدى الذي بعث به حيث تجلى في ذللك البيان العظيم. و هنـاك اتفـاق بين الأدبيـات النظريـة والسيكولوجية و الفلسفية على إن الأسـرة تعد من أهم مؤسسـات التنشئة الاجتماعية في نقل التراث الثقافي والحضاري إلى الأبناء في المجتمعات كافـة،ويعود ذلك إلى حقيقيـة إن الطفل البشري بسبب تركيبته الفسلجية يعد من أكثر الكائنات الحية التصاقاً بالكبار من أبنـاء جنسهـ وحاجتهـ

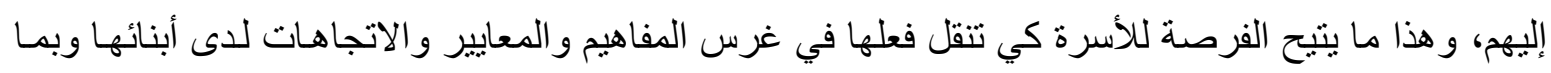

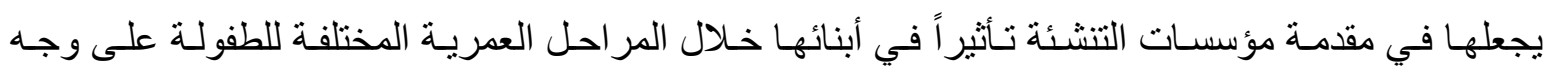
التحديد(محسن، r 919 (: 79 1). كما إن من المتفق عليه عموماً إن الاتجاهات الأساسية في المجتمع والثقافة 
يتم اكتسـابها في فترة الطفولـة كجزء مـن عمليـة التنشـئة الاجتماعيـة وبمـا يسـهم في تتميـة خبـرات الطفل الاجنماعية و الثقافية.

إن كل القيم تعد قيماً اجتماعية لأنها تكتسب منذ الطفولة من خلال عمليات التنشئة الاجتماعيـة، كما إن التغيير الذي يطر أ عليها يحدث بسبب التفاعل بين الفرد و المجتمع، ويمكن القول إن القيم عبارة عن أهداف أو لو معسيير حكم توجـه السـوك الإنسـاني وهي بالنسبة لثقافـة معينـة في زمس معين تحدد المرغوب فيسه وغير المرغوب فيه، وهي أما أن تكون إيجابية كالصدق أو سلبية كالعدوان، وهي أساسية عامـة أو إضـافية لجماعـة

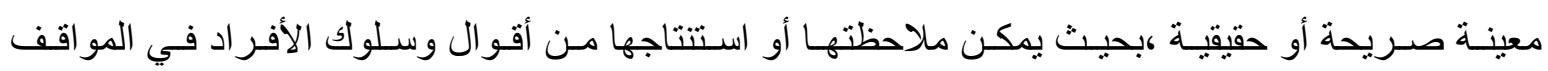

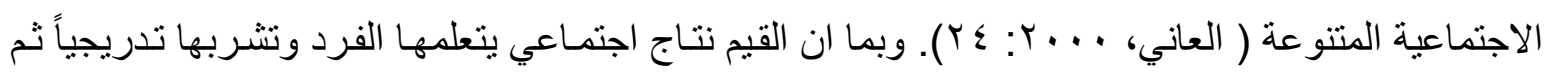

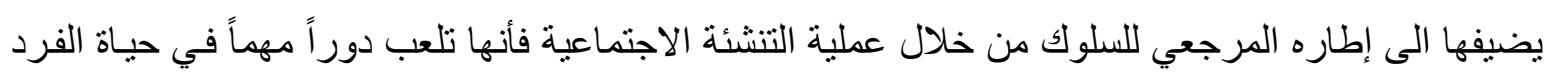
و الجماعة.

هدف البحث التعرف على دور الأسرة العر اقية في تتمية بعض القيم الاجتماعية الإيجابية لاى الأبناء. حدود البحث: يتحدد البحث الحالي بـمعلمي ومعلمات المدارس الابتدائية ضمن الرقعة الجغر افية لمدينـة بغداد

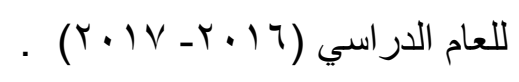

\section{تمديد الإفاهيم والامسطمات الملمية}

ا ـ الأسـرة Family: هـي البيئـة (المؤسسـة الأولىى) التـي ينشـأ فيهـا الفرد،حيـث تتشـكل فيهـا شخصـيته الاجتماعية، ومنها يكتسب الفرد لغته و عاداته وتقاليده وقيمه و عقيدنه وأساليب ومهار ات التعامل التهل مع الآخرين

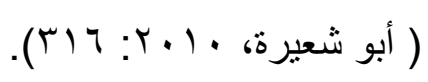

وتعرف أيضـاً بأنها: جماعة بيولوجيـة نظاميـة تتكون من رجل وامر أة تقوم بينهــا رابطـة زواجيـه مقررة

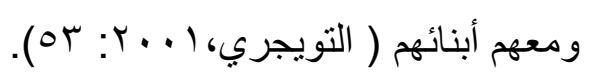

وتعرف إجرائيـاً: المؤسسـة التـي تسعى إلى بنـاء توجيه و إرشـاد أبنائهـا على ضـرورة التحلـي بقيم وأخـلاق المجتمع الذي يدعو إلى الترابط والتر احم بين أبنائها ممـا يؤدي إلى توحيدهم داخل الكيان الأسري وداخل

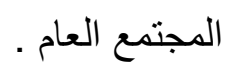

r ـ القيمValue: سـوكات مكتسبة متشـربة مـن خـلال التطبيع الاجتمـاعي لأفر اد المجتمع وتكون معلمـاً

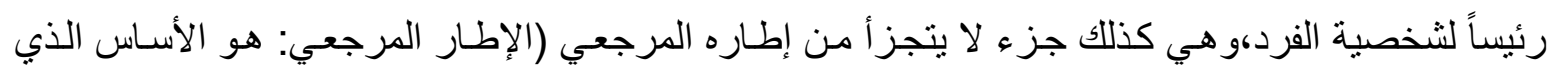

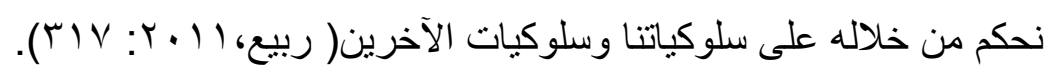
لذلك تعرف بأنها: الصفات الثخصية التي يفضلها أو يرغب بها الناس في ثقافة معينة، فالثجاعة والإيثار وضبط النفس يمكن اعتبار ها كلا على حدة،أو في مجموعها الصفات المر غوبة في كل ثقافة .

وتعرف أيضاً بأنها: اهتمام أو اختيار أو تفضيل أو حكم يصدره الإنسـان على شيء مـا مهتديا بمجموعة من

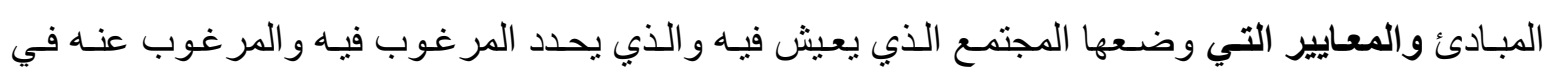

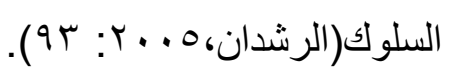


r ـ القيم الاجتماعية الايجابية:نحاول الاهتمام بها و إظهار مز اياها حتى تزيد من اهتمام الناس بها وبالتالي نستحوذ على اهتمـام الأفر اد نحو هـا حتى يتفاعلو المعها، والمقصود بـالقيم الاجتماعية الإيجابيـة في البحث هي:قيم التسامح وروح المساعدة والتو اصل الاجتماعي مع الآخرين و التي يقع ثقل تتميتها على الأسرة كونها البيئة الأولى و الأساسية في المجتمع .

\section{الفمل الثاني: الاممو الاول: الاطار النظري:}

لا يحقق المجتمع أهدافه ويستمر بوظائفه دون وجود الهدف الموحد و المنظم الذي يتمثل بـالقيم ،فتماسك المجتمع يعتمد في الأساس على قوة التوافق بين قيمه و أهدافه. ومع إن القيم ضرورة اجتماعية فهي في الوقت

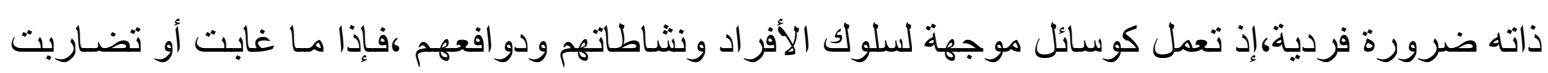

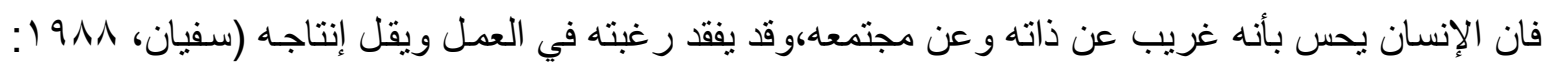

وتعد الأسرة المؤسسة التربوية الأولى التي تحتضن الطفل منذ ولادتهه ومروراً بمر احله العمريـة المختلفة،إذ ألـا أن الطفل يتأثر عن طريق التقليد السلوك كل من يحيط به من أفراد أسرته بكل ما تمتلكه من قيم. ولكل مجتمع

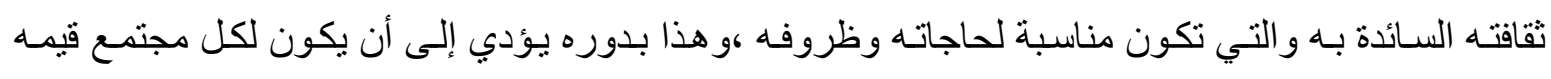
الأساسية السائدة، فالقيم ترتبط ارتباطاً وثثقاً بالنمو الثقافي السائد في المجتمع .

وتكسب الأسرة القيم لأبنائها بطريقة انتقائية من الثقافة السائدة في المجتمع فيتعلم الطفل من أسرته عن طريق الثواب والعقاب ،ويعد الإباء والأخوة الكبار أصحاب التأثير الأكبر في الأطفال الصـغار، إذ قد تصبح

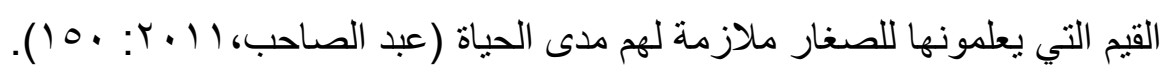
وتعد القيم في علم الاجتمـاع : حقائق أساسية هادفة في البناء الاجتمـاعي،و هي لذلك تعالج من وجهة

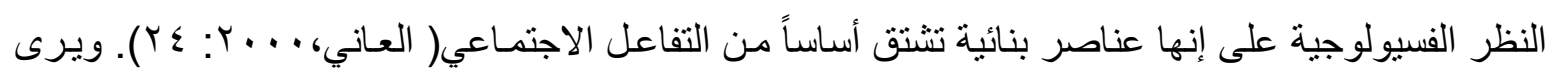

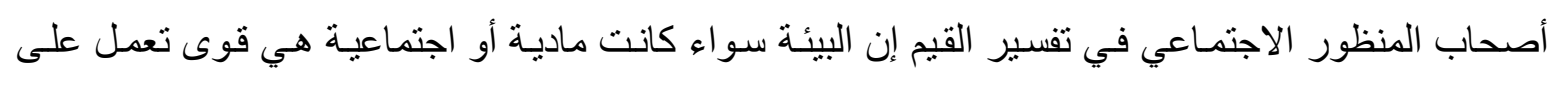

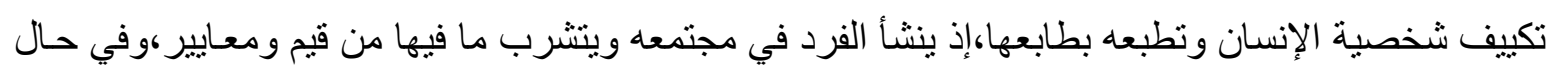

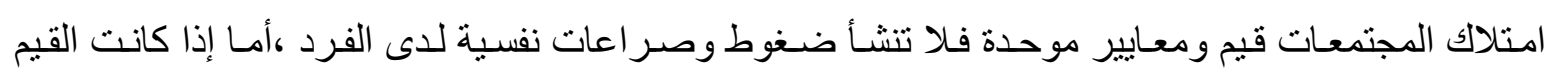

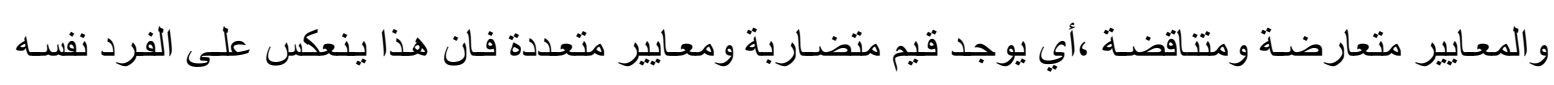

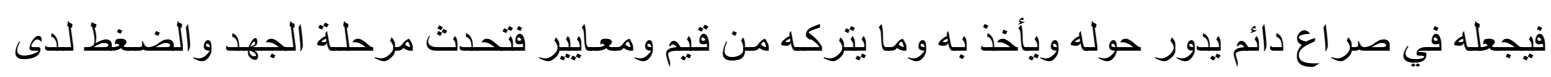

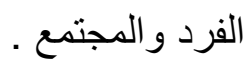

وتفسير هذه الو جهة إن للمعايير التي تقاس بها القيم أهميـة واضحة وقيمة للأفعال و الأفكار ومدى ملائمتها لمتطلبات الجماعة والمجتمع، فهي محددات لضبط سلوك الفرد ومعيار أنموذجي اجتماعي يهدف إلى ولى تحقيق تو افق أفراد المجتمع. ويؤكد الاجتماعيون على العلاقة التبادلية بين التربية كقيمة اجتماعية والقيم كونها محددات السلوك الاجتماعي، فيعتقد (باندور اهوميللر) إن القيم تتكون عن طريق التعلم و لاسيما عن طريق التقيق النمذجه و هذا يعني إن الإجراءات التدريبية المنظمة في تعلم القيم هو نفسها المتضمنة في تعلم أي نوع من 
السلوك،وتعد الأسـرة بمكوناتها الثقافيـة والاجتماعيـة المؤسسـة الاجتماعيـة الثقافيـة الأولى التي لها دور في تحديد وتشخيص القيم لدى الفرد ومن ثم العمل على تنميتها.

و القيم التربوية مفهوم جدير باهتمام الفرد و عنايته لاعتبار ات اجتماعية واقتصسادية ونفسية،والقيم أحكام

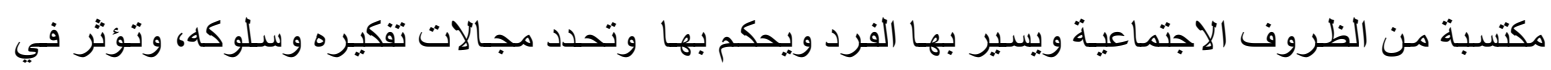

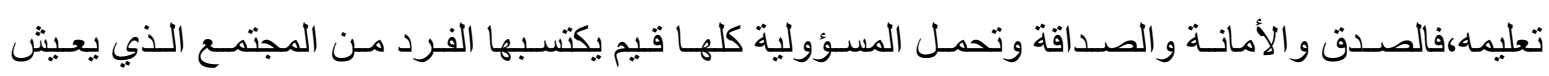
فيه،وبدون القيم التربوية يفقد المجتمع الإنساني الأصول والمبادئ التي تنظم حياته. وتزود القيم أفراد المجتمع

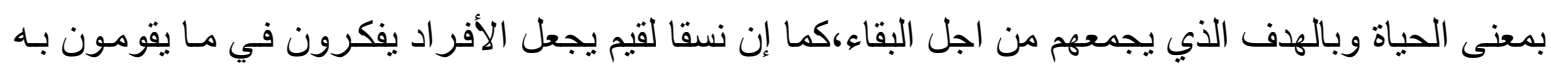
من أعمال للوصول إلى أهداف و عمليات .

وللقيم تأثيره على وحدة المجتمع وتماسكه ووحدته، إذ يتوقف تماسك المجتمع ووحدتـه إلى حد كبير

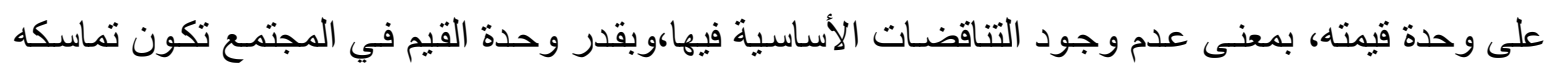

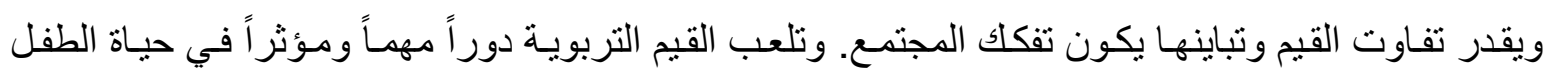

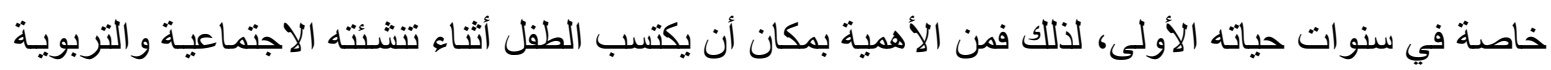

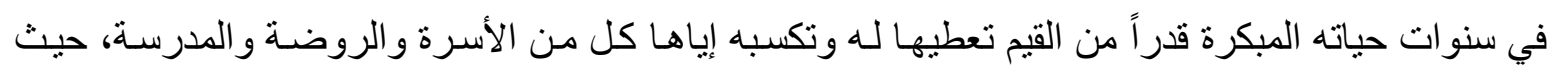
تشكل الإطار القيمي للطفل منذ الصغر ، فيعرف المرغوب فيه و المر غوب عنه، وبالتالي يستطيع التكيف مـع الجماعة التي ينتمي إليها والمجتمع الذي يعيش فيه. وتبدو أهمية القيم في قدرة الطفل على تحقيق التكامل و الاتزان في سلوكه وقدرتهه على مقاومـة القيم

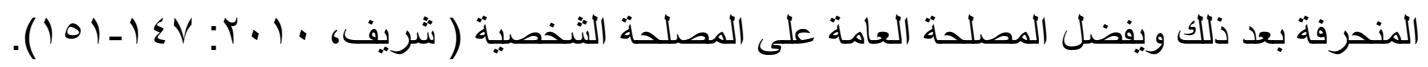

\section{فمائص القيم الاجتمباعية}

ا ـ القيم ذاتية وشخصية: نرتبط القيم بذات الفرد وشخصيته ارتباطاً وثيقاً وتظهر لديهه على صور مختلفة من التفضيلات و الاهتمامات و الاختيار ات و الحاجات و الاتجاهات و الأحكام، ممـا يجعلها قضية ذاتية شخصية يختلف الناس حول مدى أهميتها وتمثلها بـاختلاف ذواتهم وشخصياتهم وبنـاءً على ذلك يختلف الناس في حكمهر على الأشياء.

r. القيم الاجتماعية نسبية: أي تختلف باختلاف الزمان و المكان والإنسـان فتقدير ها وبيان أهميتها وجدو اها تختلف من إنسان لآخر ومن مجتمع لآخر ومن مكان لآخر ومن زمان لآخر فهي إذًا نسبية وهي مثنار جدل

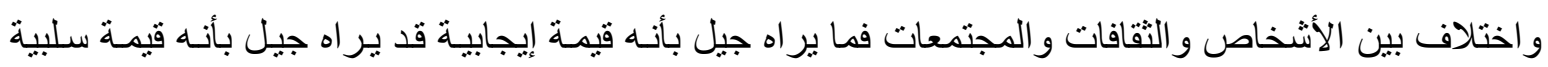
و هكذا.

r. القيم الاجتماعية تجريدية: فهي معاني تتسم بالموضو عية والاستقلالية تتضح معانيها الحقيقية في السلوك الذي تمثله و الو اقع الذي تعيشه، فرغم إنها معاني كلية ومطلقة ومجردة إلا أنها لا تكون إلا إذا تلبست بـالو اقع و السلوك أي يؤمن بها الإنسان كموجه له ويحتضنها في سلوكه. 
؛ ـ القيم متدرجة: أي تنتظم في سلك قيمي متغير ومتفاعل حيث تترتب القيم عند الفرد ترنيباً هرمياً تهيمن فيه بعض القيم على بعضـها الآخر فللفرد قيم أساسية مسيطرة لها درجـة كبرى من الأهمية وتأتي في قمـة الهرم القيمي و هناك قيماً أقل أهمية مما يشكل عنده نسقاً قيمياً داخلياً متدرجاً،ويظهر السلم القيمي واضحاً جلياً في مو اقف الحياة عندما تتعارض القيم المهمة مع تلك التي هي اقل أهمية فيعمل على الاختيار بينها والتفضيل و إخضاع بعضها لبعض.

ه. القيم إنسانية: أبي أنها تختص بهذا الإنسـان و هذا من خـلال التعريف الثـامل للقيم الاجتماعية، وإن كان لاى الحيو انات معايير وتفضيلات تقوم عليها قو انين حياتها إلا أنها لا نرتقي لتصل لمفهوم القيم الاجتماعية لاى الإنسان .

צ. القيم الاجتماعية تمتلك صفة الضدية: فكل قيمة اجتماعية إيجابية نجد أن في مقابلها قيمة سلبية، فمثلاً

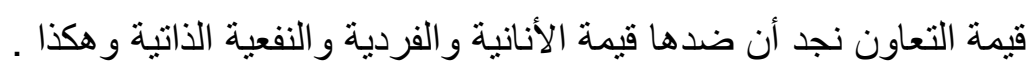
V. من خصائصها أنها متعلمة: ينو ارثها الأجيال وتتناقلها البشرية بواسطة القدوة والتعليم المباثر و غير ذلك ته من طرق تعلم القيم الاجتماعية. ^. ومن خصائصها أن لها إلزام جمعي: فالمجتمع يلزم أفر اده بعدد من القيم على حسب أهميتها وترتيبها في السلم القيمي ونسق القيم الخاص بذلك المجتمع . 9. ومن خصائصها أنها مترابطة: فلكل مجتمع نسق قيمي متر ابط قد اصطفت فيه القيم الاجتماعية وترتبت حسب ثقافة ذلك المجتمع وظروفه المحيطة ولها نوع من الترابط فلا يمكن أن تنتزع إحدى تللك القيم لتحل

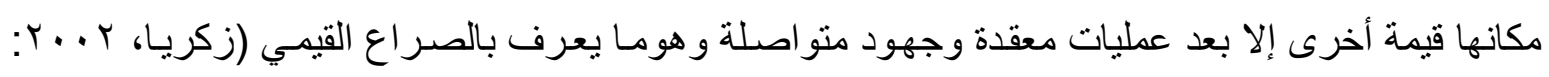

\section{همادر اكتساب القيم الاجمتماعية}

بما أن القيم الاجتماعية أحكام وقوانين وتتظيم لأحكام عقلية فهي بحاجة شديدة إلى منهجيـة علميـة قويـة في استتباطها حتى تتسم تلك القيم بالصدق والثبات وتصـلح للتعميم، ومن المصـادر التي يعتمد عليها في التي استنباط القيم الاجتماعية هي:

أولاً / الثـريعة الإسـلامية: وهـي المصدر الأول والصـحيح لاستنباط القيم الاجتماعيـة، وعلى قدر رجوع

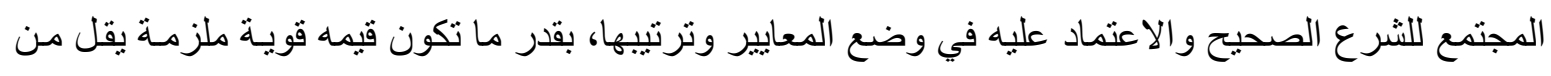

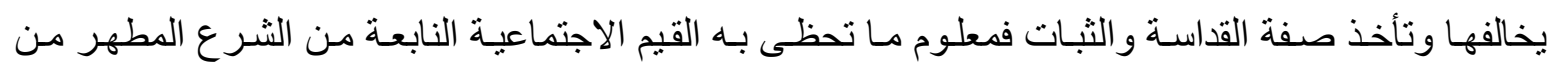
احتر ام و إلز ام و التي أخذت قوتها من قوة مصدر ها مثل: بر الو الدين و الرحمـة والتعـاون فمثنل هذه القيم لها رصيدها الكبير من الأدلة الدالة على أفضليتها والحث عليها والتحفيز على امتثالها ولست هنا بصدد الاستدلال

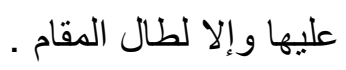
ثانيـاً / الواقع التعليمسي: فالقيم مكتسبة بـالتعليم و التربيـة والتدريب والتطبيق وبقدر مـا يحظى المجتهـع من فرص تعليمية ويتطور التعليم فيه بقدر مـا تظهر حاجـات ذللك المجتمع ويتلمس مطالبه الحقيقية التي تسعى ملى 
لإسعاده بخلاف المجتمعات التي ينتشر فيها الجهل فقد تغفل وتتعامى عن احتياجاتها الحقيقية وتتشـغل بـالأمور السفيهة وتتحط اهتماماتها ويختل سلمها القيمي، فالتعليم مصدر أصيل ور افد قوي من روافد استنباط القيم الاجتماعية بأن يجعل مقنتاً ومرتباً للقيم الاجتماعيـة المطلوبـة والتي يرى المختصـون الإخـلال الحاصل بها

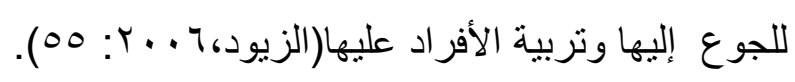
ثالثاً / الواقع الاقتصادي: ومعلوم حاجة الإنسان للمال و أنه قوام الحياة و القيم مرتبطـة ارتباطـاً وثنيقاً بالوضـع الاقتصـادي فالناس تسعى للمـال وتسعى للحصول على الحياة الكريمـة بو اسطة تحسين وضعها الاقتصـادي، وتختلف المجتمعات الغنية عن المجتمعات الفقيرة في قيمها الاجتماعية نظر اً لاختلاف حاجات الناس في كلا المجتمعين ففي حين يبحث الأفر اد في المجتمعات الغنية عن الكماليات و الرفاهية و الفكاهة ،يبحث نظر ائهم في المجتمعات المعدمة عن لقمة العيش التي تسد الرمق وتحفظ الحياة من الهلاك فلا يعتبرون مواكبـة العالم في

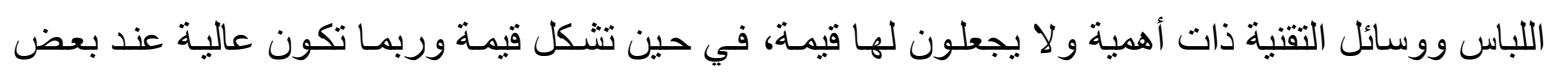

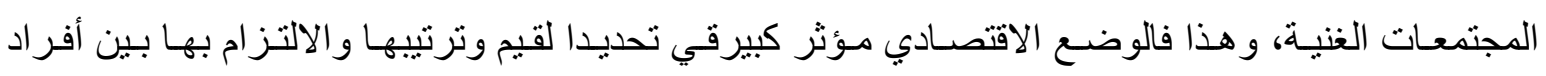
المجتمع. رابعاً / الواقع السياسي: و هو من المصادر التي تشكيل القيم الاجتماعية وتقوم بالتفضيل والترتيب بينها بنـاء على الوضـع السياسـي للمجتــع ومعلـوم الفـرق بـين المجتمعـات القويـة و المجتمعـات الضـعيفة في القيم

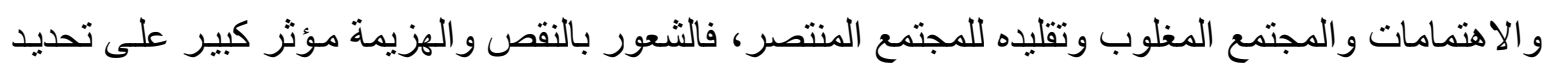

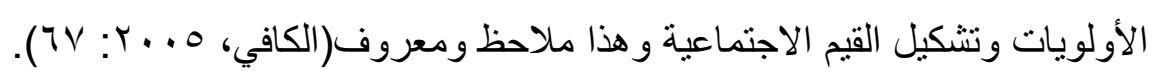

\section{المعور الثاني: دراسات سابقة}

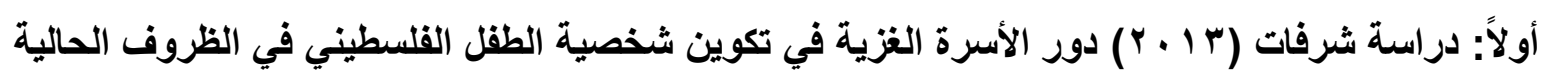
هدفت هذه الدراسة التعرف على دور الأسرة الغزية في بنـاء شخصية الطفل الفلسطيني و الكشف عن دور الو الدين في تحقيق الصحة النفسية لأطفالهم في ظل الظروف الحاليـة ومعرفة أسباب حاجـات الطفل الفلسطيني للرعاية الأسرية المباثرة و الوقوف على أسباب الأزمات الأسرية التي تساعد على تشكيل ظواهر

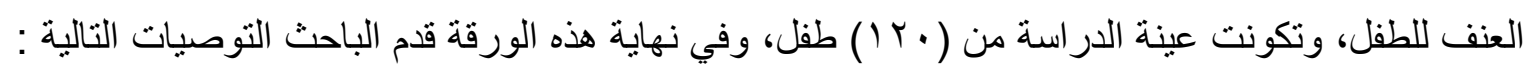

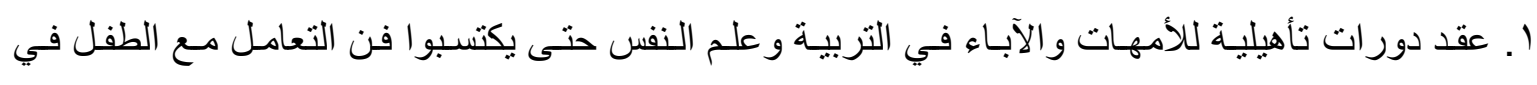

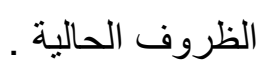

r. من الضروري تلبية حاجات الطفل الفلسطيني حتى لا ينجر و لا ينحرف سلوكه ويرتكب المحرمات .

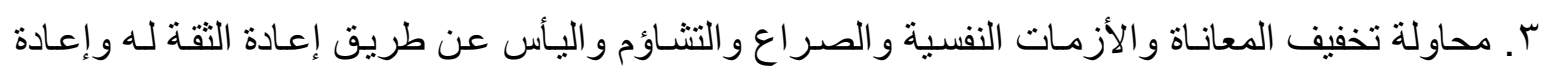

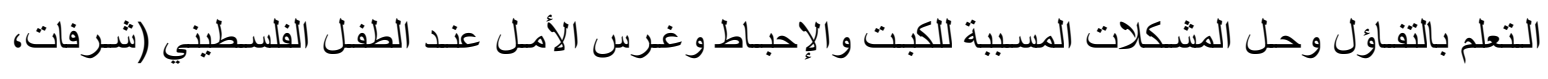

( ) (IV:r

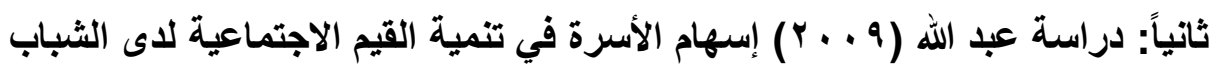

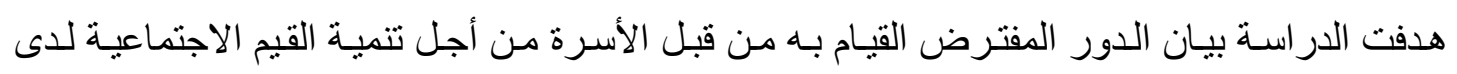

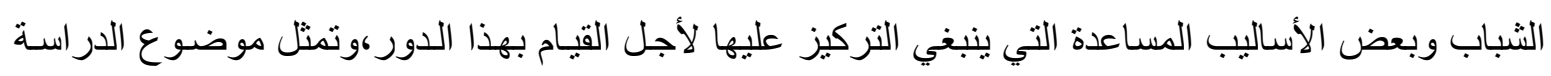


الإجابـة على السؤال الآتي: مـا الدور الواجب على الأسـرة القيام بـه في سبيل تتميـة القيم الاجتماعية لدى الثباب؟ وتكونت عينة الدراسـة من (79 ) شـاب، واستخدمت الدراسـة المنهج الوصفي لأهميـة دراسـة القيم

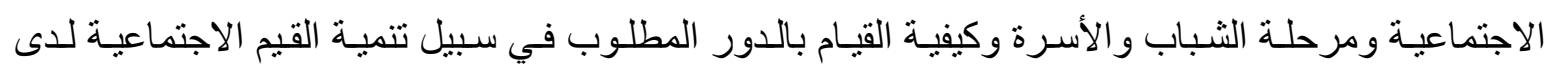
مرحلة الثباب ـ أما أهم نتائج الدراسة فقد أكدت على الدور المطلوب من الأسرة في تتمية القيم الاجتماعية

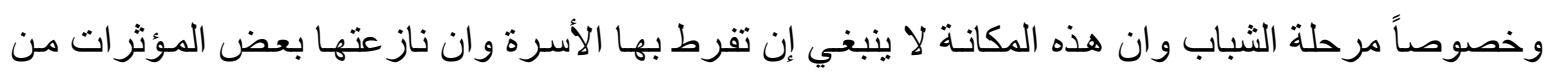

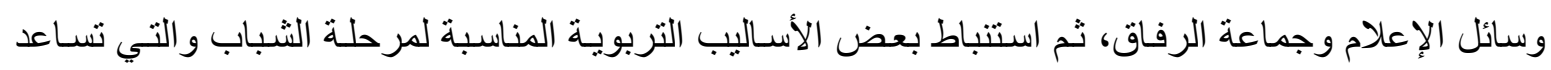
الأسرة على عملية تنمية القيم الاجتماعية ومنها:

ا ـ تقوية جانب الإيمان بالله عز وجل. r. تتمية روح الأخوة الدينية و التر ابط المجتمعي. r. تماسك المجتمع وثر ابطه. ع. وجود البيئة الأسرية السليمة. ه.وجود القدوة الإيجابية وتوفر ها.

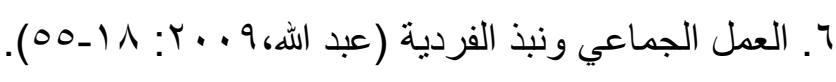

النمل الثالث : اجراءات البمث

تتضمن هذه الإجر اءات التعرف على الأدبيات المستخدمة في البحث و المر احل التي يتم اعتمادها في بناء الأداة، فضلاً عن إجراءات تطبيقها على عينة البحث إلى جانب الوسـائل الإحصـائية المعتمدة في البحث

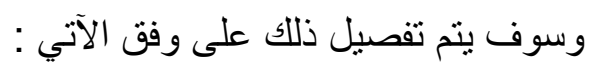
ا ـ القيام بلراسـة استطلاعية على عينة مكونـة من ( 0 ) معلم ومعلمـة ،وثم توجيـه السؤ ال(ماهو دورك كمربي للاططفال في تتمية بعض القيم الاجتماعية الإيجابيـة كالتسـامح وروح المساعدة والتواصل الاجتمـاعي مع الآخرين في ظل الظروف الر اهنة). r. . بعد جـع الإجابـات من المفحوصين والاطلاع على الأدبيـات وأيضـا الاستعانة بـالخبراء المختصين تم تحويل الإجابات إلى فقرات وتكون خلالها الاستبيان النهائي الذي كان يحوي(·) فقرة موجهة إلى عينـة من معلمي ومعلمات المدارس الابتدائية. r. للتأكد من صدق أداة البحث/ قامت الباحثة باستخدام الصدق الظاهري وذلك بعرض الاستبيان على لجنة من الخبر اء، وأجريت بعض التعديلات البسيطة عليه وبذلك اشتمل على( TV ) فقرة . ؛. اختيار عينة البحث: تم اختيار عينة البحث عشو ائياً من مجتمع البحث الأصلي لمعلمي ومعلمات المدارس الابتدائية في بغداد وطبق على عينة البحث وحسب المدارس الموجودة كعينة لمجتمع البحث وكما موضـح في

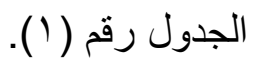

جدول رقم ( 1 ): أسماء الددارس الابتدائية وعدد المعلمين والمعلمات في عينة البحث

\begin{tabular}{|c|c|c|c|c|}
\hline المجموع & عدد المعلمات & عدد المعلمين & اسم المدرسة & ت \\
\hline 1. & - & 1. & مدرسة المجد الابتدائية & 1 \\
\hline
\end{tabular}




\begin{tabular}{|c|c|c|c|c|}
\hline ro & 10 & 1. & مدرسة الفاتح & $r$ \\
\hline 10 & 1. & 0 & مدرسة النيل الابتدئية & $r$ \\
\hline $1 \cdots$ & 1. & - & مدرسة ابي طالب & $\varepsilon$ \\
\hline$r$. & 1. & 1. & مدرسة الشهامة & 0 \\
\hline 1. & 0 & 0 & مدرسة الانطلاق & 7 \\
\hline 1. & - & 1. & مدرسة موسى بن نصير & $\mathrm{v}$ \\
\hline $1 \ldots$ & 0. & o. & المجموع & \\
\hline
\end{tabular}

• ـ الوسائل الإحصائية ثم استخدام قانون الوسط المرجح

\section{الفصل الرابع: عرض النتائج وتفسيرها}

1 ـ تم تحقيق هدف البحث و هو التعرف على دور الأسرة العراقية في تتمية بعض القيم الاجتماعيـة الإيجابية

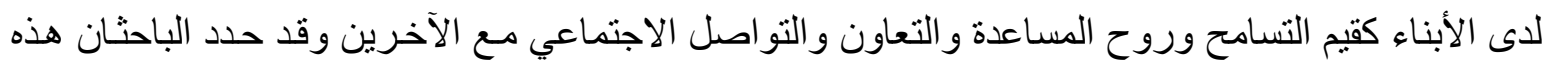
القيم و الملحق ( رقم ا ) يوضح ذلك .

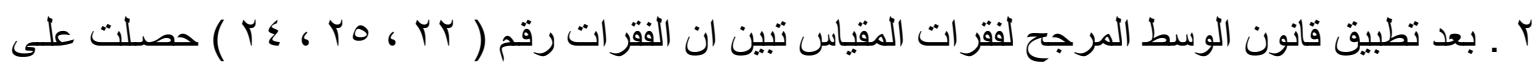
أعلى قيمة وهي ( ^. r )، و الفقرات هي: (بث روح التسامح والابتعاد عن المواقف المتطرفة، إزالة الخلافات بين الأطر اف المتناحرة، تنمية الثعور بالوحدة الوطنية بين مختلف الطوائف).

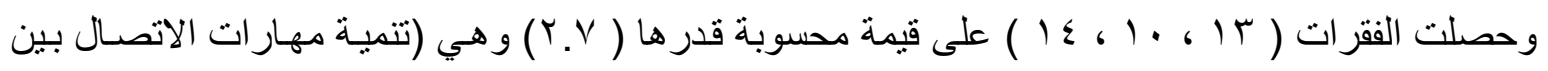
أفر اد الأسرة، عدم استعمال الألفاظ التي توحي بـالتمييز العرقي أو الطائفي، عدم السماح للأطفال بمثـاهدة

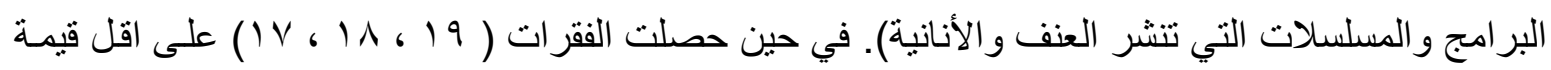

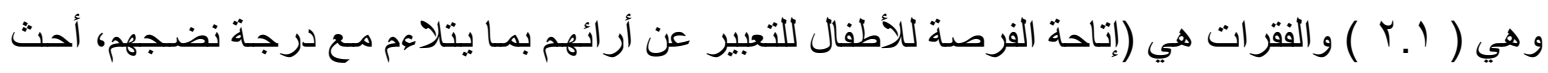

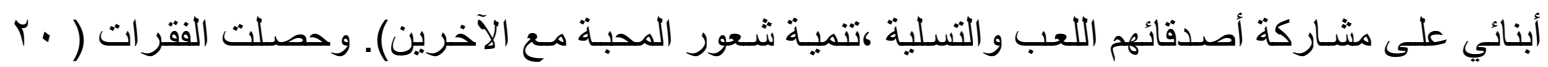
، ، (Y) على اقل قيمة أيضاً وهي (Y) و الفقرات هي : (التعاون مع الأصدقاء في قضـاء حاجاتهم و التواصل معهم،الاشتر اك مع الآخرين في أفر احهم وأحز انهم) وكما موضح في جدول رقم (Y). جدول رقم ( r) : القيم الإيجابية التي تسعى الأسرة إلى تنميتها لاى الأبناء

جدول رقم (r (r) : قيمة الوسط المرجح لفقرات المقياس

\begin{tabular}{|c|c|c|}
\hline القيمة المحسوبة & الفقرات & $ت$ \\
\hline r.A & بث روح التسامح والابتعاد عن المواقف المتطرفة & 1 \\
\hline$\overline{r . \Lambda}$ & إزالة الخلافات بين الأطراف المتناحرة & r \\
\hline Y.A & تنمية الثعور بالوحدة الوطنية بين مختلف الطوائف & $r$ \\
\hline Y.V & ت تنمية مهارات الاتصال بين أفراد الأسرة & $\varepsilon$ \\
\hline Y.V & علم استعمال الألفاظ التي توحي بالتمييز العرقي أو الطائفي & • \\
\hline Y.V & عدم السماح للأطفال بمشاهدة البرامج والمسلسلات التي تنشر العنف والأنانية & 7 \\
\hline r. .7 & اعتماد مبادئ الاين الإسلامي الحنيف في التعامل مع الآخرين & $\mathrm{v}$ \\
\hline r. .7 & أوصي ابني عندما يخطأ بحق زميله أن يعتذر منه ويطلب المسامحة & $\Lambda$ \\
\hline Y. & أثشجع أبنائي على العلاقات الاجتماعية الطيبة مع الآخرين & 9 \\
\hline Y. & أوصي ابني بمساعدة المحتاج & 1. \\
\hline$Y .7$ & مساعدة الجيران وقت الحاجة & 11 \\
\hline r.० & أتحمل بعض الأخطاء من الجار & ir \\
\hline
\end{tabular}




\begin{tabular}{|c|c|c|}
\hline Y.0 & تقديم الهاليا للآخرين في المناسبات & 14 \\
\hline Y.Q & إبداء الاستعداد المادي والمعنوي لخدمة المجتمع المحلي & $1 \varepsilon$ \\
\hline Y.६ & حث الأطفال لحضور المناسبات ألدينية والاجتماعية سواء على مستّوى العائلة & 10 \\
\hline Y.द & مد يد العون للطلبة المحتاجين & 17 \\
\hline Y.\& & إثشاعة روح الألفة من خلال الزيارات المتبادلة مع الآخرين & IV \\
\hline Y.r & أتدخل لمصالحة أبنائي غند حدوث خصومة بينهم & 11 \\
\hline Y.r & أكون قدوة لأبنائي في مساعدة الآخرين & 19 \\
\hline Y.r & اصطحب أبنائي معي عندما أتو اصل مع أقربائي & r. \\
\hline Y.Y & مناقشةة الخلافات بموضوعية (دون تحيز) عند وقوعها & YT \\
\hline r.r & السيطرة على الانفعالات الثخصية & rr \\
\hline Y.1 & إتاحة الفرصة للأطفال للتعبير عن أرائهم بما يتلاءم مع درجة نضجهم & rr \\
\hline Y.1 & أحث أبنائي على مشاركة أصدقائهم اللعب والتسلية & $r \varepsilon$ \\
\hline Y.1 & تتمية شعور المحبة مع الآخرين & ro \\
\hline Y.P. & التعاون مع الأصدقاء في قضاء حاجاتهم والتو اصل معهر & r4 \\
\hline Y.P. & الاشتَراك مع الآخرين في أفراحهم وأحزانهر & TV \\
\hline
\end{tabular}

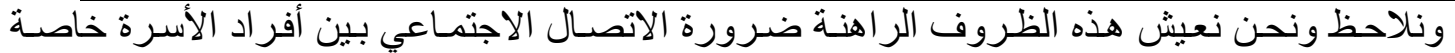

و أفر اد المجتمع عامة.

إن العلاقات الاجتماعية القوية كانت أداة و آلية للضبط السلوكي والاجتمـاعي بوصفها أكسبت أعضـائها

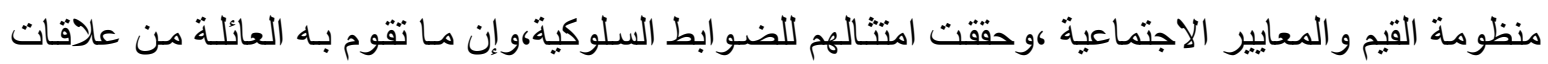
وروابط اجتماعية قوية له تأثثر فاعل في حماية العائلة من التهديدات الاجتماعية و الثـعور بـالأمن والطمأنينة

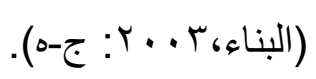

إن العلاقات الاجتماعية بين العائلة وجماعات الجيرة شغلت دور ها كآلية للضبط السلوكي و الاجتمـاعي و مصدراً لإشباع الحاجة، وان ما تقوم به العائلة من علاقات وروابط اجتماعية قوية له تأثثير فاعل في حمايـة العائلة من التهديدات الاجتماعية والثعور بالأمن و الطمأنينة. و أكدت هذه الدر اسة أيضاً على وجود علاقة بين ارتباط العائلة بعلاقات وروابط اجتماعيـة قويـة مـع جماعاته القر ابة وبين توفير الحماية من التهديدات الاجتماعية لأعضائها. و هناك علاقة بين التنشئة الاجتماعية السليمة في العائلة وبين اكتساب و التزام الأعضاء بالقيم و المعايير الاجتماعية وان الطفل يكتسب روح التعاون

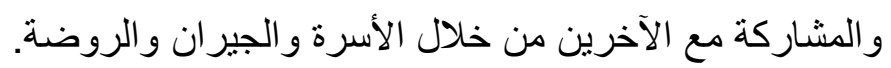

وقد أوضحت العديد من الدراسات ان الأطفال الأكثر كرماً، أولئلك اللذين تقاسموا مـع أصدقائهم كثيراً

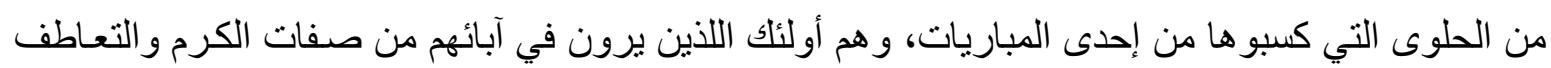
و الرعاية و الحب، ومعنى ذللك أن مشـاهدة الطفل لمـا يقوم بـه و الداه من سلوك خلقي هو اكبر مشـجع لـه أن

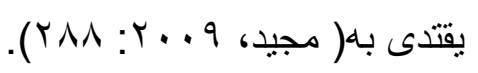
الاستنتاجات: في ضوء نتائج البحث توصل البحث إلى الاستنتاجات الآتية :

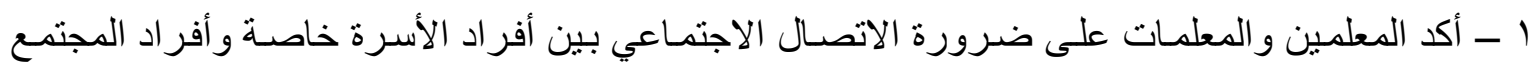
عامة لما له من أهمية في تقوية الأواصر الاجتماعية . r - يرى كل من المعلمين و المعلمات ان للأسرة دور فعال في تطوير القيم الاجتماعية ومعالجة مشكلاتها . 
r- يرى كل من المعلمين والمعلمـات إن العلاقات الاجتماعيـة القويـة بين الأسر لها تأثير فاعل في حمايـة العائلة من التهديدات الاجتماعية التي قد يتعرضو الها ويجعلهم يشعرون بالأمن و الطمأنينة.

ـ - من الممكن تتمية القيم الاجتماعية في المجتمع من خـلال التخطيط لبر امج توعيـة دقيقة للأسـر العر اقيـة

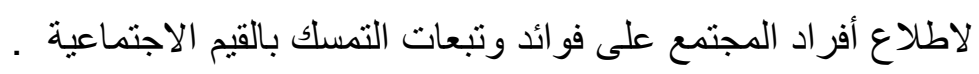

\section{التوصيات}

ا . عدم التحدث داخل الآسرة عن أمور ومسـائل طائفية تدعو إلى التقرقة و إنمـا يجب أن تكون الأحاديث داعية أو تدعو إلى التو اصل الاجتماعي ومساعدة الآخرين في كافة ظروفهم الاجتماعية والاقتصادية . r. عقد ندوات نربوية في التربيـة وعلم النفس لحث الآسر العر اقيـة على ضـرورة التواصل الاجتمـاعي مـع الآخرين.

r. غرس حب الآخرين واحتر امهم وصيانة حقوقهم في نفسية الطفل،يث تبدأ هذه التجربة في تعريف الطفل بحقوقه وحقوق إخو انه واحتر ام هذه الحقوق وزرع القناعة الذاتية في نفسه. ع. غرس الحب و الاحتر ام لايه للمجتمع المحلي الصغير الذي يتواجد فيه سكنه وتعيش فيه أسرته. ○ـ تعزيز ثقافة الحوار و المشاركة والتسامح مع الآخرين. 7 ـ. تعويد الأطفال على التعايش و التعاون مع الآخرين. V. تتمية اتجاهات التفاهم والأخوة والتعاون التي يجب أن تسود الناس.

الاتشزحمات

ا ـ إجـر اء در اســة مماتلــة تتـــاول دور الأسـرة العراقيـة في التقليـل مـن العنف بـين الأطفـال داخـل الأسـرة و المدرسة. r. إجر اء در اسة مماثلة تتناول دور الأسرة العر اقية في تتمية بعض القيم الدينية. المصادر 1- أبو شعيرة، خالد محمد.( • ( ب):الدخل إلى علم التربية،مكتبة الدجمع العلمي للنشر و التوزيع،عمان،الأردن.

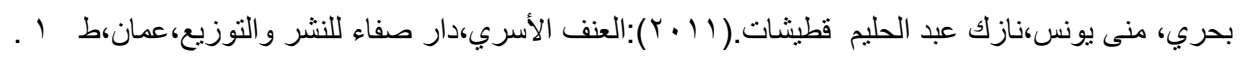

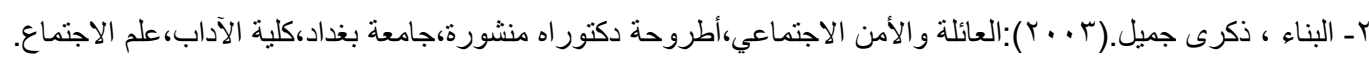

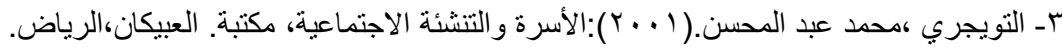

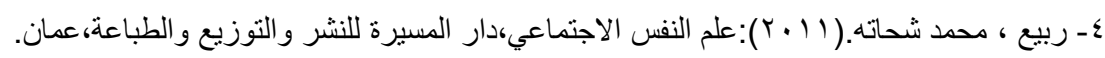

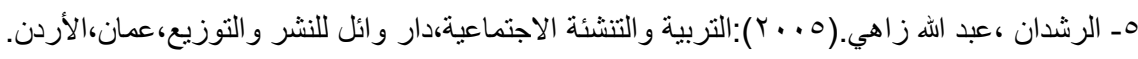

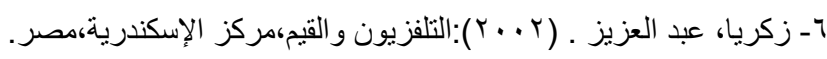

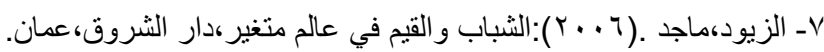

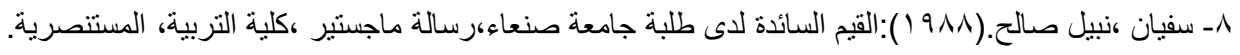

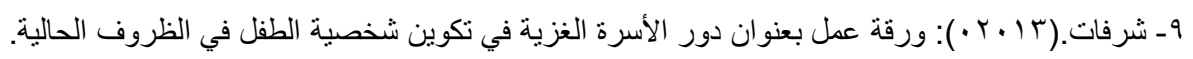

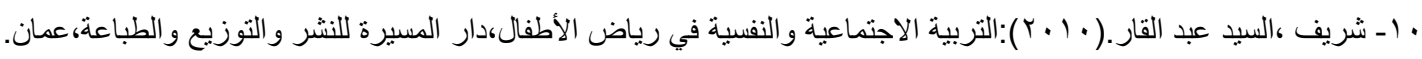

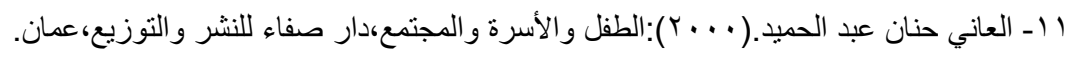




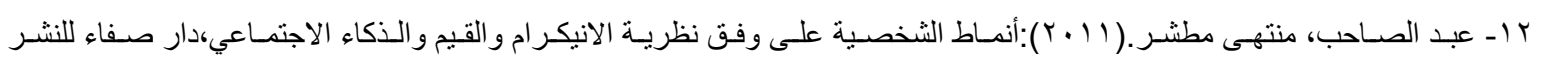

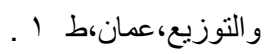

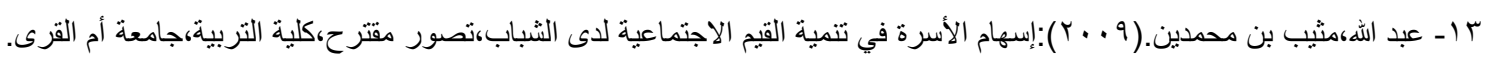

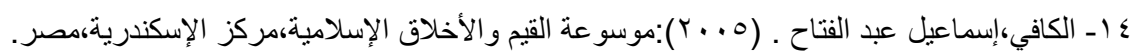

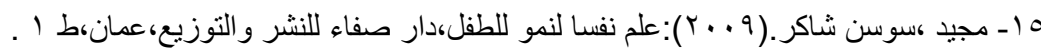
7 ا ـ محسن ،محي الدين.(r 91 ( ):مشكلات التفاعل الاجتماعي بين التجديد و المعالجة،دار . المعارف، القاهرة.

ملحق رقم (1) : يوضح القيم الإيجابية التي تسعى الأسرة إلى تنميتها لاى الأبناء

\begin{tabular}{|c|c|c|c|c|}
\hline لابداً أقوم بها & متوبة بهنيا & كبيرة أقوم بهـة & 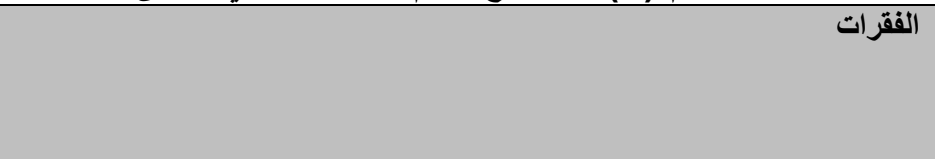 & $ت$ \\
\hline & & & أوصي ابني عندما يخطأ بحق زميله إن يعتذر منه ويطلب المسامحة & 1 \\
\hline & & & أندخل لمصاّلحة أبنائي عند حدوث خصومة بينهم & $r$ \\
\hline & & & أشجع أبنائي على العلاّقات الاجتماعية & $r$ \\
\hline & & & أوصي ابني بمساعدة المحتاج & $\varepsilon$ \\
\hline & & & مساعدة الجيران وقت الحاجة & $\bullet$ \\
\hline & & & أتحمل بعض الأخطاء من الجار & 7 \\
\hline & & & أكون قدوة لأبنائي في مساعدة الآخرين & $\mathrm{V}$ \\
\hline & & & اصطحب أبنائي معي عندما أتواصل مع أقربائي & $\Lambda$ \\
\hline & & & تقديم الهدايا للآخرين في المناسبات & 9 \\
\hline & & & علدم استعمال الألفاظ التي توحي بالتمييز العرقي أو الطائفي & 1. \\
\hline & & & إبداء الاستعداد المادي والمعنوي لخدمة المجتمع المحلي & 11 \\
\hline & & & المحلة الأطفال لحضور المناسبات الاينية والاجتماعية سواء على مستوى العائلة أو & ir \\
\hline & & & عدم السماح للأطفال بمشاهدة البرامج والمسلسلات التي تنشر العنف والأنانية & ir \\
\hline & & & تنمية مهارات الاتصال بين أفراد الأسرة & $1 \leq$ \\
\hline & & & مناقشة الخلافات بموضوعية (دون تحيز) عند وقوعها & 10 \\
\hline & & & السيطرة على الانفعالات الشخصية & 17 \\
\hline & & & إتاحة الفرصةٌ للاطفال للتعبير عن أرائهم بما يتلاءم مع درجة نضجهم & IV \\
\hline & & & أحث أبنائي عل بمشاركة أصدقائهم اللعب والتسلية & 11 \\
\hline & & & تنمية شعور المحبة مع الآخرين & 19 \\
\hline & & & التعاون مع الأصدقاء في قضاء حاجاتهم والتواصل معهم & $r \cdot$ \\
\hline & & & الاشتراك مع الآخرين في أفراحهم وأحزانهم & Y \\
\hline & & & تنمية الثعور بالوحدة الوطنية بين مختلف الظوائف والقوميات & rY \\
\hline & & & مد يد العون للطلبة المحتاجين & $r r$ \\
\hline & & & بث روح التسامح والابتعاد عن المواقف المتطرفة & $r \leqslant$ \\
\hline & & & إزالة الخلافات بين الأطراف المتتاحرة & ro \\
\hline & & & إثاعة روح الألفة من خلال لزيارات المتبادلة مع الآخرين & $r 7$ \\
\hline & & & اعتماد مبادئ الاين الإسلامي الحنيف في التعامل مع الآخرين & rV \\
\hline
\end{tabular}

